\title{
Los instrumentos de escritura y registro en el noreste peninsular en época republicana (s. II-I a.n.e.) como indicadores de romanización
}

Writing and registering instruments in

NE Iberian Peninsula during the Late

Republican period $\left(2^{\text {nd }}-1^{\text {st }}\right.$ c. $\left.B C\right)$ as

indicators of Romanization

\author{
Oriol Olesti Vila \\ Universidad Autónoma de Barcelona \\ Oriol.Olesti@uab.cat
}

Resumen: Este trabajo analiza la presencia de instrumentos de escritura y registro en distintos yacimientos del NE de la Península Ibérica durante los s. II-I a.n.e. A partir de un primer inventario, se valora su rol en el contexto histórico y cultural del periodo, analizando especialmente su relación con el registro epigráfico documentado en estos yacimientos.

Palabras clave: Stylus. Caja de sello. Signaculum. Romanización.

Abstract: This paper analyzes the presence of writing and registering instruments in several settlements of the NE Iberian Peninsula $\left(2^{\text {nd }}-1^{\text {st }} \mathrm{c}\right.$. BC), attempting to assess their historical, cultural and economic interest, as a reflection of the process of integration within the Roman world. It also analyzes the relation between these writing instruments and the local epigraphy.

Key words: Stylus. Seal-boxes. Signaculum. Romanization.

Recepción: 23.10.2019 | Aceptación: 10.11.2019

Proyecto: Este trabajo ha sido realizado en el marco del proyecto de investigación "Paisajes de la Hispania Romana 2" (HAR2017-87488-R), financiado por el Ministerio de Economía y Competitividad. 


\section{Introducción}

En los últimos decenios, la identificación y excavación de numerosos yacimientos de los s. II-I a.n.e. en el NE de la Península Ibérica (a grandes rasgos, el actual territorio de Catalunya) ha puesto de manifiesto la complejidad del fenómeno de conquista e integración de estos territorios bajo el dominio romano. Ya hace tiempo se constató la diversidad de situaciones y procesos que se desarrollaron en estas áreas, con fenómenos de abandono/destrucción de algunos oppida frente a la continuidad y promoción de otros, fundaciones urbanas, y el surgimiento de un poblamiento rural notablemente dinámico (una síntesis en Aquilué et al. 2000; Nolla et al. 2010; Olesti 2017). La conquista romana no fue homogénea ni en el tiempo ni en sus estrategias de control, aunque es posible identificar algunas pautas de dominio y sumisión bien definidas: destrucción de los centros defensivos indígenas más preeminentes, colaboración y pacto con una parte importante de las élites locales, exclusión y sometimiento de otros sectores del mundo indígenas, introducción de nuevas formas productivas y de poblamiento, desarrollo de un nuevo poblamiento rural, refundaciones urbanas, etc.

En este panorama, la identificación cada vez más concluyente de numerosos establecimientos vinculados a la presencia militar romana (bien como campamentos propiamente dichos, o como centros logísticos) ha planteado un nuevo paradigma y una cierta contradicción con lo tradicionalmente asumido, puesto que un territorio alejado a partir de la década del 180 a.n.e. de los frentes bélicos peninsulares, mostraba una elevada presencia del ejército romano (Ble 2015).

Esta 'eclosión' de la presencia militar romana, además, se data en algunos casos a partir de la década del 170-160 a.n.e. (como por ejemplo en el caso del nuevo recinto militar documentado en Emporion, Castanyer et al. 2015), pero en general responde a una cronología algo posterior, que podríamos centrar en la segunda mitad del s. II a.n.e., y una pervivencia hasta la primera mitad del s. I a.n.e. Parece pues evidente que la génesis de esta estructura no responde ni al momento inicial de la conquista del NE, ni tampoco a los conflictos militares que afectaron a la zona con posterioridad. Recientemente, algunos autores han planteado la repercusión que en el NE Peninsular tuvieron episodios como las Guerras Címbricas (que solo colateralmente afectaron a la Citerior), como punto de partida de esta estructura militar. Se trata del llamado 'estrés bélico' que generó en numerosas provincias vecinas este con- 
flicto. Sin embargo, sin negar su importancia, lo mismo podría decirse del periodo anterior, cuando este territorio pudo verse inmerso como zona de retaguardia, y de 'estrés bélico', del conflicto de las Guerras Celtibéricas, o con posterioridad respecto a la Guerra Social, que sabemos implicó directamente el envío de tropas de la provincia a la misma Italia. Es evidente que desde el momento en que el NE peninsular fue un territorio de dominio consolidado, y con recursos tanto económicos como humanos de efectivo drenaje, su rol fue clave en la estrategia romana de dominio y explotación de las provincias occidentales. Además, las cronologías claramente de mediados o tercer cuarto del s. II a.n.e. de algunos yacimientos clave (Cabrera de Mar, Puig Castellar de Biosca, incluso algo anterior, Can Tacó o Mas Gusó), revelan sin duda una génesis anterior al conflicto címbrico (uid. Principal y Ñaco 2017; Pera y Vidal 2016; Ruiz y Padrós 2015).

Algo diferente sería la situación durante la primera mitad del s. I a.n.e., cuando la trascendencia de conflictos como las Guerras Sertorianas, en primer lugar, y después la Guerra Civil, afectó directamente a estos territorios, ya no como zona de retaguardia sino directamente como escenarios de trascendentes combates.

Sin embargo, y pese a los avances en el campo de la arqueología militar romana en el noreste, una parte mayoritaria del poblamiento de los s. II-I a.n.e. siguió siendo de filiación indígena, tanto a nivel de poblamiento concentrado (con la pervivencia de numerosos oppida), como de poblamiento disperso (granjas o talleres). Esta 'relativa' continuidad local — pues también son numerosos los yacimientos indígenas de nueva fundación que se documentan en esta fase-, dio lugar a un mundo productivo híbrido, con elementos de clara tradición indígena (continuidad de la producción agropecuaria, del sistema de almacenaje en silos, de la cerámica de cocina a mano...) y novedades de filiación romana, como el uso de nuevas técnicas constructivas (tegula, opus signinum), productivas (lacus, prensas, dolia), e incluso urbanísticas, con la eclosión de ciudades romanas ex novo (Olesti 2017).

En este contexto, la difusión de la escritura y el uso de la lengua ibérica y latina ha tomado nueva importancia, puesto que se ha convertido - especialmente entre arqueólogos e historiadores- en un fósil director del grado de aculturación romana, a pesar de los problemas que supone la proyección del registro escrito, además muy limitado en sus documentos, para la interpretación de los fenómenos culturales (Beltrán 2005). 
Trabajos recientes como los de J. Ferrer, N. Moncunill o A. G. Sinner, han puesto de manifiesto el fuerte impulso que la presencia romana dio a la epigrafía ibérica en el NE, con el fuerte incremento de textos documentados precisamente entre la $2^{\text {a }}$ mitad del s. II y la $1^{\text {a }}$ del s. I a.n.e. ${ }^{1}$ A su vez, la aparición pero escasez relativa de documentos en latín, podía llevar a pensar en una moderada y tardía latinización, algo contradictorio con el grado de integración notable $-\mathrm{y}$ antigua - de algunas élites locales, y con la desaparición de la lengua ibérica en la primera mitad del s. I d.n.e.

Es probable que parte de esta aparente contradicción proceda de nuestro propio registro epigráfico y arqueológico, que ha permitido conservar preferentemente las inscripciones sobre soporte duro, en especial cerámico (es decir, grafitos), un tipo de escrito habitualmente breve y que puede corresponder a una fase inicial en la alfabetización (uid. Beltrán 2005). Esta conservación sería mucho más precaria en el caso de la inscripciones sobre piedra y bronce, canal privilegiado para la documentación oficial romana, pero cuyos soportes fueron frecuentemente reutilizados en épocas posteriores, o que simplemente tuvieron una difusión más reducida en estas cronologías en el NE. En cambio, los textos escritos sobre material perecedero (tablillas, papiros), ya mayoritarios en la cultura literaria romana de los s. II-I a.n.e., difícilmente se han conservado, por lo que su hipotética presencia en nuestra zona de estudio parecía hasta hace poco fuera de nuestro alcance. El uso de estos soportes perecederos para tareas de registro, obliga también a analizar esta función.

\section{Los materiales de escritura y registro}

En este contexto, la aparición de materiales de escritura (y registro) en algunos yacimientos del NE peninsular de los s. II-I a.n.e., llamó ya hace algún tiempo nuestra atención. ${ }^{2}$ Se trataba en primer lugar de styli, los estiletes

1 No entraremos a fondo en su bibliografía, pero baste con destacar trabajos como Sinner y Ferrer 2016, así como la reciente obra colectiva editada por Sinner y Velaza 2019.

2 Una investigación preliminar sobre estos instrumentos fue presentada en "Styli, tablillas y sellos como indicios de romanización. El caso del N.E. Peninsular (s. II-I a.n.e.)", durante las III Jornadas predoctorales en estudios de la Antigüedad y la Edad Media. Culturas en contacto: conflicto, asimilación e intercambio, celebrada en la Universidad Autónoma de Barcelona, noviembre 2016. Una primera identificación y contextualización de estos instrumentos está en curso de publicación en Olesti e.p. El presente trabajo es deudor del previo, al cual nos remitimos para el mejor conocimiento de las piezas y su contexto arqueológico, y pretende ir más allá en el análisis socio-cultural de estos objetos. Es posible que por azares de la publicación éste segundo trabajo aparezca antes del anterior. 
generalmente en hueso utilizados para la escritura sobre tabulae ceratae, pero pronto se incorporaron al catálogo otros elementos: las cajas de sello para preservar la impronta del signaculum (en hueso o bronce), las espátulas para alisar la cera, y finalmente los propios anillos signatorios, signaculum (Feugère y Bozic 2004; Feugère 1995; Sarri 2018). ${ }^{3}$ Estos instrumentos se asocian normalmente al uso de tablillas, aunque algunos styli podrían ser utilizados para escribir sobre plomo (por ejemplo, los estiletes en bronce). Estos instrumentos, en general, fueron utilizados para la escritura (las cajas de sello y el anillo signatorio, junto a los elementos de sujeción, serían los elementos que garantizarían la inviolabilidad de la tabula cerata), pero no debemos olvidar otras posibilidades: las tablas de cera podían tener un uso como documentos contables (un ábaco), y las cajas de sello y sellos podían no solo autentificar cartas/tablillas (Andrews 2013), sino otro tipo de objetos (sacos, bolsas, incluso papiros). Por ello, preferimos hablar en este artículo también de instrumentos de registro, pues la falta de conservación de las tablillas (aunque hay dos ejemplares parcialmente conservados, uno en Camp de les Lloses, otro en Burriac, así como un paralelo en ZIAC-Niel, Toulouse) no permite precisar con total seguridad su única función como texto escrito o misiva.

Instrumentos de escritura (y registro) de los s. II-I a.n.e. - bien por separado o asociados entre ellos - han sido documentados en un conjunto de 27 yacimientos del NE Peninsular y áreas vecinas, con un total de más de un centenar de objetos, en su mayor parte en contextos específicos y cronologías bien determinadas (fig. 1). No presentamos en este estudio el corpus de estos elementos, que ya ha sido publicado recientemente (Olesti e.p.), pero sí una tabla sinóptica de los hallazgos (uid. Apéndice), así como resumiremos brevemente las características del conjunto, a partir de lo cual plantearemos nuevas propuestas de interpretación.

Los yacimientos analizados responden a tres grandes grupos: ciudades de fundación o re-fundación romana (es decir, de origen indígena, pero que durante el periodo republicano sufrieron obras urbanísticas de envergadura), establecimientos de tipo militar (tanto defensivo como logístico), y finalmente oppida o yacimientos de filiación indígena.

3 No incluimos en este inventario objetos como los cálamos o los tinteros (tanto en cerámica como en bronce) debido a la dificultad de valorar su presencia en los yacimientos del NE. Se trata de piezas que no se identifican habitualmente como tales, y por ello pasan desapercibidos en los inventarios arqueológicos. Es muy probable que su mejor identificación permita reconocer su presencia en yacimientos del NE peninsular. 


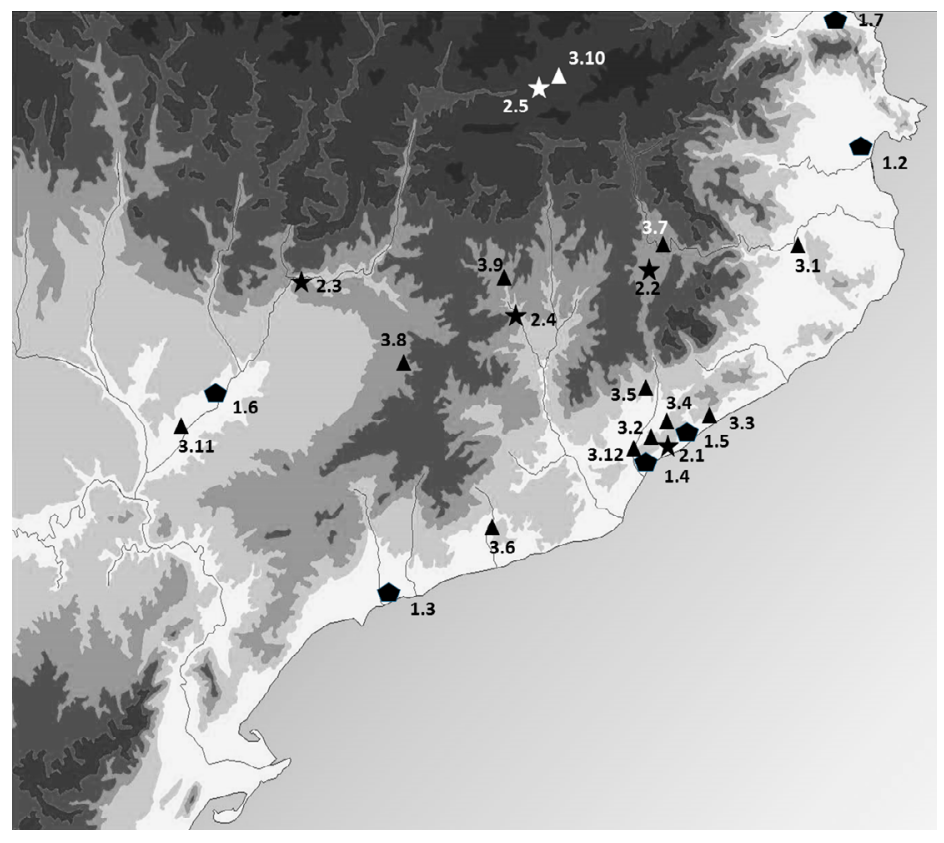

Fig. 1. Mapa de distribución de los instrumentos de escritura y registro documentados en el noreste de la Península Ibérica y en el sur de Francia. Los números corresponden a los yacimientos recogidos en la tabla reproducida en el anejo (elaboración propia).

El volumen de instrumentos de escritura documentados en todos ellos es desigual. El más numeroso es el que corresponde a las ciudades del primer grupo (con casi la mitad del total de elementos, 53), lo que parece lógico dado el papel que debió jugar la escritura en estos centros, abiertos al comercio (muchos de ellos se sitúan en la zona costera), en algunos casos con presencia contrastada de gentes y libertos de origen itálico o romano, y en contacto directo con la administración provincial. El segundo grupo corresponde a los establecimientos de tipo militar, con un conjunto de 21 elementos, lo que tampoco parece sorprendente, dada la difusión del hábito de la escritura tanto entre las tropas romanas como entre sus proveedores. Destaca finalmente el conjunto de 30 objetos documentados en contextos indígenas, básicamente oppida, que merecerán una especial atención.

Respecto al tipo de instrumentos documentados, destaca en primer lugar el elevado volumen de styli (57 ejemplares), seguido de las cajas de sello (30), los anillos signatorios (13), ${ }^{4} \mathrm{y}$ finalmente las espátulas de cera (4).

4 En este caso, se han considerado tan sólo aquellos anillos signatorios aparecidos en yacimientos y contextos donde se han documentado también otros instrumentos de escritura, excepto los casos excepcionales de Soses y el del Tossal de Baltarga 
Finalmente, es necesario un breve comentario referente a este corpus: una parte importante de estos objetos no fueron identificados en su momento por parte de los arqueólogos que excavaron en estos yacimientos. Especialmente en el caso de los styli, su confusión con agujas de cabello, o husos, los ha llevado a veces a no ser publicados adecuadamente, o directamente a permanecer sin publicar. Algo similar ocurre con las cajas de sello: mal conocidas (o a veces, conservadas solo parcialmente), tanto en hueso como en bronce, han permanecido en muchos casos sin ser estudiadas ni publicadas, y lo mismo ha ocurrido con las mucho más escasas espátulas metálicas de cera. Nuestro inventario, además, no ha sido exhaustivo, puesto que hemos estudiado aquellos yacimientos que han sido publicados de manera amplia, o que permitían un fácil acceso a sus materiales. La conclusión parece evidente: este conjunto que aquí presentamos es tan sólo una parte reducida de los instrumentos de escritura que deben conservarse en muchos otros yacimientos del período, y en especial en los de tradición indígena, en los que por desconocimiento o por apriorismo no se consideraba factible, no se intuía, su presencia. Creemos que con la publicación de éste y otros trabajos sobre este tipo de objetos (p.ej. Simón 2012; 2016; 2018; e.p.; Mayayo e.p.), el volumen de materiales identificados va a incrementarse de manera muy notable.

\section{3. ¿Una alfabetización más amplia? ¿Una latinización encubierta?}

Estos instrumentos de escritura y registro plantean una primera pregunta: su número importante - que posiblemente aumentará en un futuro próximo - cuestiona la visión generalizada de una baja alfabetización en el NE peninsular en época republicana. Parece evidente que se escribía más de lo que se suponía y de lo que indicaba el registro arqueológico a partir de las escasas inscripciones conservadas, bien fueran rupestres, sobre plomo o sobre cerámica (una idea ya planteada por Beltrán 2005). No podemos hablar de generalización, pero sí de una notable presencia de este tipo de instrumentos en yacimientos de todo tipo, en algún caso notablemente indígenas y de carácter secundario. ${ }^{5}$ Además, si como creemos, estos instrumentos son indicativos de

(establecimiento íntimamente vinculado al yacimiento del Castellot de Bolvir, que sí los presenta). La presencia de signaculum es muy numerosa en yacimientos de s. II-I a.n.e., y no siempre puede vincularse con seguridad a la actividad de registro y escritura, aunque esa sea una de sus funciones principales. Es especialmente significativa su relación con la presencia militar (uid. infra).

5 Recientemente, y a partir del interesante caso del poblado ibérico del Palomar de Oliete, donde se han documentado dos magníficos styli en hueso en un contexto claramente 
unos textos redactados sobre tablillas, estaríamos frente a escritos más complejos que los simples grafitos de propiedad, lo que implicaría de nuevo un grado de alfabetización superior al generalmente considerado.

Este corpus de objetos, sin embargo, no deja de ser la constatación material indirecta del objeto de estudio que más nos interesaría y que realmente no hemos conservado: los textos escritos. Por ello, saber qué se escribía, en qué lengua se escribía, y por quién se escribía, queda aún lejos de nuestro conocimiento. Nuestro corpus documental tan sólo nos permitirá esbozar algunas primeras propuestas. Intentaremos por ello analizar con detalle algunos elementos significativos que quizás puedan aportar luz a estas preguntas.

La vinculación de los instrumentos de escritura con la presencia romana (bien fuera militar o civil-administrativa) parece la más clara. Su presencia en los centros urbanos de época republicana no presenta mayores problemas, y los mismo puede decirse de los de filiación militar/logística (Olesti e.p.). La vinculación de estos establecimientos, directa o indirectamente, a la red administrativa o militar romana del momento (hasta cierto punto, las dos caras de una misma moneda) llevan a inclinarse inicialmente por el uso del latín en buena parte de las hipotéticas tablillas redactadas.

Sin embargo, podríamos intentar ser más precisos, y plantearnos qué tipo de documentos pudieron redactarse, e incluso si en algunos casos esta lengua pudo haber sido la ibérica. Un posible indicio sería analizar el contexto epigráfico conocido en estos establecimientos, y analizar la presencia de la lengua latina o ibérica en sus inscripciones. Hasta cierto punto, sería lógico suponer que la lengua utilizada comúnmente sobre otros soportes epigráficos (cerámica, bronce, plomo) podría ser indicativa de la lengua utilizada sobre estos soportes perecederos.

En el caso de ciudades como Tarraco o Emporion, la epigrafía republicana es suficientemente conocida como para documentar el carácter híbrido de su población, con una población de origen ibérico (testimoniada tanto en la epigrafía monumental como en grafitos cerámicos), otra latina (romana o itálica) y finalmente griega (Díaz 2009). También interesante es el caso de Valentia, con un claro predominio de los textos en latín, pero con una signi-

indígena, I. Simón plantea la misma cuestión (2018, 24). También N. Barrandon 2013 se plantea este fenómeno, indicando por ejemplo la práctica ausencia de documentos ibéricos en plomo a partir de la conquista romana, lo que podría a mi modo de ver ser otra de las consecuencias de la difusión de estos instrumentos de escritura. 
ficativa presencia de grafitos ibéricos. ${ }^{6}$ Más curioso sería el caso de Baetulo o Iluro, donde la presencia de grafitos ibéricos (e incluso alguna inscripción ibérica sobre piedra) es muy superior a la latina, prácticamente inexistente en contextos republicanos. Casos similares serían los de Ilerda y Ruscino, donde la presencia de grafitos ibéricos es notable, superior a los latinos. ${ }^{7}$

Más allá de las ciudades, sin embargo, el panorama es aún más complejo. Así, en el caso de Cabrera de Mar (bien estudiado recientemente por Sinner y Ferrer 2016) se ha puesto de manifiesto el gran número de grafitos ibéricos existentes en este centro, abierto claramente a las influencias itálicas, que contrasta con la ausencia total de grafitos latinos. Aquí, sería posible pensar que frente a una población de origen indígena (local pero también probablemente venida de otras zonas, en forma de auxilia), y que ha dejado sus testimonios en forma de grafitos, existiría otra comunidad (minoritaria, pero sin duda existente en este centro) cuyos textos no se han conservado pues se redactaron sobre soportes perecederos, testimoniados por los styli documentados. Ello no excluiría, en absoluto, que también la población que utilizó el ibérico pudiera hacer uso de este tipo de documentos perecederos, pero al menos explicaría la ausencia sorprendente de grafitos latinos.

Este caso contrasta, sin embargo, con el yacimiento de La Cabañeta, recientemente estudiado (Mínguez y Díaz 2011). Esta fundación de tipo urbano, de finales de s. II a.n.e., con un contingente importante de población italo-romana, ha dejado un corpus de grafitos con clara preponderancia del latín ( 22 en latín, 14 en ibérico y 2 numerales en griego), un paisaje epigráfico notablemente distinto del de Cabrera de Mar. No parece casual tampoco que se hayan documentado 23 styli en el yacimiento (Mayayo e.p.), un número tan sólo comparable a casos como Emporion o Tarraco, lo que también va en la línea de una presencia efectiva de población originaria de la península italiana en el lugar.

Quisiéramos destacar también, por paradójico, el caso de la Torre dels Encantats (Arenys de Mar), un pequeño oppidum ibérico, que pervivió duran-

6 Del total de 34 grafitos identificados, 18 son latinos, 7 ibéricos y 3 griegos (interpretados más como obra de comerciantes que de libertos de origen oriental), lo que demuestra el rol de población originaria de la península italiana en este momento (un fenómeno similar se documenta en La Cabañeta, Mínguez y Díaz 2011). Es habitual que conviva un hábito de escritura en tablillas con uno más sencillo de escritura breve sobre cerámica por parte de un mismo colectivo, de probable origen militar, Adams 2003.

7 Agradecemos a J. Ferrer el acceso a su registro sobre los grafitos ibéricos documentados en estos yacimientos. $C f$. Rebé 2016. 
te los s. II-I a.n.e., y donde se hallaron dos styli y un pondus marcado con un entalle. Aquí, se conservan más de una veintena de grafitos ibéricos, pero también uno en latín, $M A R$, que parece corresponder a un nomen latino. Creemos que se trata de un ejemplo de temprana latinización y adopción de la onomástica latina por parte de la población indígena. La presencia de instrumentos de escritura en el lugar no hace sino confirmar la difusión de la escritura entre las poblaciones locales, quizás más ibérica que latina en lugares como este.

Un caso similar sería l'Esquerda (Roda de Ter), un oppidum que presenta a finales del s. II a.n.e. un carácter ya notablemente marginal y reducido, poco que ver con su fase ibérica plena, y que sin embargo ha documentado una tapa de una cápsula de sello en esta reocupación tardía. Coherente con este contexto, se conocen tan sólo 2 grafitos del yacimiento, ambos ibéricos.

Finalmente, en un ejemplo aún más evidente de continuidad indígena, mencionaríamos el yacimiento de la Torre Roja (Caldes de Montbui), donde un oppidum abandonado durante el s. II a.n.e. se reocupa a principios del s. I a.n.e., con un marcado carácter indígena local. En el yacimiento se ha hallado un stylus de hueso, mientras que a nivel epigráfico se conoce un solo grafito, ibérico.

A manera de sumario, podemos afirmar que la coincidencia entre yacimientos con instrumentos de escritura y yacimientos con grafitos ibéricos es apabullante. ${ }^{8}$ En realidad, excepto el Tossal de Baltarga (en el cual no hemos documentado por el momento ningún grafito ibérico, pero es indudable el contexto mayoritariamente indígena de sus estructuras), en todo el resto de yacimientos inventariados con materiales de escritura se han documentado grafitos ibéricos, casi exclusivamente en el caso de los de filiación indígena, y casi exclusivos o ampliamente mayoritarios en el caso de los de filiación logística-militar ¿Se escribió entonces con estos instrumentos en lengua latina o ibérica?

Parecería lógico que en este tipo de yacimientos la lengua usada en los textos escritos sobre soportes perecederos fuese la ibérica, puesto que ésta fue la mayoritaria en el lugar. Sin embargo, no podemos descartar la existencia de un fenómeno de diglosia: la lengua latina sería utilizada en las comunicaciones de carácter más oficial y formal (las documentadas por este tipo de instrumentos de escritura), mientras que se reservaría al ámbito más doméstico los grafitos sobre cerámica, en muchos casos meras indicaciones de propiedad sobre el

8 De nuevo aquí el caso del Palomar de Oliete sería coincidente, Simón 2018. 
objeto. Ello permitiría explicar dos fenómenos: por un lado, la relativa escasez de documentos escritos en latín en un territorio, como el NE peninsular, ampliamente integrado a la órbita romana desde el s. II a.n.e., y por otro, la sorprendente y rápida desaparición de la escritura ibérica a principios del s. I d.n.e. Si el latín hubiera sido más utilizado de lo que parece indicar el registro documental de los s. II-I a.n.e., especialmente entre las poblaciones indígenas, la latinización precoz de estas poblaciones (al igual que indica Estrabón (Strab. 3.1.6) para el caso de los turdetanos) sería más coherente, y también por ello lo sería la desaparición rápida de la escritura ibérica en la primera mitad del s. I.

En otras palabras, es posible que los instrumentos de escritura que hemos documentado sean un indicio de una latinización incipiente, más precoz e intensa de lo que el registro epigráfico conservado - dominado por los grafitos sobre cerámica- nos indica. ${ }^{9}$ Es sin duda una hipótesis difícil de contrastar, pero explicaría mejor la rápida desaparición del ibérico poco tiempo después, y la fuerza del latín ya casi omnipresente en nuestro registro epigráfico a partir de época augústea.

\section{Registro e inventario}

Queremos también en esta contribución analizar el caso de los anillos signatorios, un tipo de objeto arqueológico poco valorado. Nuestro inventario ha recogido 13 ejemplares de los s. II-I a.n.e., de los cuáles 3 en contextos urbanos (un número que sin duda se incrementaría con un estudio más específico), 7 en yacimientos de filiación militar, y 3 en oppida o contextos indígenas.

En principio, su presencia en contextos arqueológicos ha sido habitualmente vinculado a una función de adorno personal, y no tanto a su función como sello. Sin embargo, algunos ejemplos literarios demuestran la importancia de este objeto como parte de la identidad de su poseedor, tanto a nivel público (en el caso de magistrados u oficiales del ejército) como privado (al permitir marcar la correspondencia, o algunas posesiones, del individuo en cuestión). ${ }^{10}$ En este sentido, es altamente significativo el ejemplo de Valentia, donde en los niveles de destrucción de la ciudad fueron identificados los cuerpos de diversos soldados ejecutados en el contexto de la toma pompeyana de la ciudad (Ribera 2014). Justamente, uno de los personajes que más llamó la atención fue el cuer-

9 Un fenómeno similar, aunque de cronología algo posterior, se dio en Britania o el delta del Rin, Derks et al. 2002; Hanson et al. 2002.

10 Una reciente síntesis en Mayer 2014. En Olesti e.p. se recogen algunas interesantes menciones sobre la cuestión en las fuentes literarias referentes a los siglos II-I a.n.e. 
po de un hombre de mediana edad (el más longevo de los 14 documentados), asesinado cruelmente, y que ha sido interpretado como el oficial de más rango de la guarnición, ajusticiado en pleno foro. Poco se ha destacado, sin embargo, que el cuerpo apareció con algunos elementos que nos parecen significativos: un anillo signatorio en su dedo índice (con una piedra de pasta vítrea), y en las inmediaciones del cuerpo dos estiletes y una tapa de una cápsula de sello. En otras palabras, el oficial - y quizás sus acompañantes, scribae? - conservaron hasta el último momento los elementos propios de su función administrativa (recordemos el caso del cuestor Ti. Sempronio Graco en el 151 a.n.e. y las tablillas recuperadas en Numancia, Plut. Tib. Sempr. 6). La conexión entre oficiales del ejército, su función de comandante, y los instrumentos de escritura y registro parece clara. ${ }^{11}$ En este caso, pocas dudas hay sobre la filiación romana o itálica de buena parte de la población de la ciudad, que ha quedado registrada en los grafitos sobre cerámica (de Hoz et al. 2013).

Sin embargo, los sellos también tenían una importante función en el mundo civil (Marshmann 2015; Pombo 2014). Cicerón recoge algunos casos de su trascendencia en el uso de tablillas y documentos contables personales (privados, pero con valor probatorio ante la administración) que presidían la vida de la provincia Narbonense durante el gobierno de Fonteyo (Cic. Font. 2.3, 4.11). Pero también en la vida privada los sellos tenían una importante función, no sólo para la autentificación de documentos como cartas o testamentos, sino incluso para una función mucho más práctica, como el sellado de productos en la despensa familiar, como realizaba la propia madre de Cicerón en su finca, cuando sellaba (obsignabat) las botellas para evitar que se consumieran escapando a su control (Cic. Fam. 16.26). ${ }^{12}$

En el caso de nuestro inventario, y teniendo en cuenta su presencia en yacimientos donde han aparecido instrumentos de escritura-registro, consideramos a los anillos signatorios como parte de estos materiales, en algunos casos directamente vinculados al sellado de tablillas (y la presencia de cajas de sello y styli así lo atestiguaría), pero en otros casos quizás podrían servir para el marcaje de otros elementos, como sacos, bolsas, e incluso objetos cerámicos.

11 Debemos también recordar el caso del gobernador de la Ulterior, L. Piso, quién perdió en Corduba su sello y encargó inmediatamente uno nuevo al orfebre (Cicero, In Ver. 2.4.56). También los anillos signatorios eran útiles para la identificación de los cadáveres de los oficiales fallecidos en combate, como en algunos casos de la segunda y tercera guerra púnica (Liv. Per. 23.12; Ap. Pun. 15.104; 15.108). obsignabat, ne dicerentur inanes aliquae fuisse, quae furtim essent exsiccatae". 
Este tipo de marcaje puede tener su reflejo en nuestro registro arqueológico. En los últimos años han sido documentadas algunas piezas, en especial pondera (pesos de telar elaborados en arcilla), con improntas de entalles, es decir, con la impronta de un anillo signatorio. Autores como Ignacio Simón han destacado el interés de este tipo de objetos, que muestran la utilización de signacula en el marcaje de objetos, en especial pondera (Simón 2018), con una iconografía propia de los entalles de tipo helenístico (o mejor, helenístico-romano). En el área del NE marcas de este tipo se han documentado al menos en tres yacimientos. En primer lugar, sobre pondera localizados en unos silos del s. II-I a.n.e. en Sta. Coloma de Gramanet, con la iconografía de una mujer sedente de espaldas a un posible trípode (de la Pinta 1993, 146, fig. 29). En segundo lugar, sobre pondera de la Riera Seca (Vallbona d'Anoia), un yacimiento del s. II-I a.n.e., ubicado en el llano, no excavado, con la iconografía de un cánido en movimiento (De la Pinta 1993, 149, fig. 2). Finalmente, en Torre dels Encantats, con la marca de un motivo geométrico en un sello oval, de nuevo sobre pondera (Garcés 2013, 269). En este último caso, el hallazgo coincide con un oppidum en el que se han documentado instrumentos de escritura.

La utilización de estampillas sobre cerámicas o pondera en época ibérica no es novedosa en el NE catalán (p.ej. Cura 1971), pero se trata de motivos claramente diferenciados de la impronta de entalles, un fenómeno que parece solo documentarse durante los s. II-I a.n.e., y que a mi modo de ver debe ponerse en relación con el uso de los anillos signatorios como identificadores de propiedad o identidad.

No se trata de un fenómeno exclusivo de Citerior. En el Cabezo de la Cruz (Almedinilla), un yacimiento destruido durante el s. II a.n.e., se localizaron diversos pondera con la impronta de un entalle decorado en su parte superior, marca sin duda de un signaculum figurado (Vaquerizo et al. 2011, 220, figs. 401-403).

A nuestro modo de ver, todos estos pondera marcados deben ser puestos en relación con la necesidad de diferenciar las producciones, bien de los propios pondera, bien de las producciones textiles que con ellos se elaboraban. En todos estos yacimientos, los pondera con marcas de entalles conviven con pondera marcados de otras maneras (grafitos post-cocción, grafitos pre-cocción, marcas geométricas...), por lo que parece claro que existía una necesidad de marcaje de al menos una parte de las piezas. Que en algunos casos se utilizaran entalles, y por lo tanto anillos signatorios, supone la adopción de una forma más espe- 
cíficamente romana de marcaje, y quizás fuera indicativa de un marcaje más oficial, quizás vinculado a unas producciones segregadas, fuera del ámbito estrictamente doméstico. Suponer la existencia de un marcaje específico para producciones (probablemente textiles) específicas, podría llevarnos a pensar en contribuciones fuera del ámbito local, quizás vinculadas precisamente a la logística militar o tributaria. Se trata sin duda de una hipótesis, pero sería coherente con el incremento mayor a lo largo de los ss. II-I a.n.e. del hábito de registro.

Más sorprendente aún es el caso de una crétula sellada procedente de Jaén (Almagro 2017), que probablemente estaba asociada a un documento en papiro, que se dataría a finales del s. III a.n.e. La crétula en arcilla, que muestra indicios de las cuerdas que la fijaban al papiro, debió ser originalmente de barro sin cocer, pero se conservó por haberse convertido en cerámica tras un incendio. La impronta se realizó con un entalle helenístico decorado con la imagen de un caballero con lanza. Como destaca Almagro (2017, 425), este tipo de crétulas pueden asociarse en el mundo helenístico a documentos de tipo burocrático, en especial la percepción de tasas e impuestos, pero no puede descartarse una cronología algo posterior, ya bajo el dominio romano.

En este mismo trabajo, también M. Almagro publica un magnífico entalle de Villaricos, de origen e iconografía púnica, y con el antropónimo ' $m n d / r$ grabado sobre la barba del personaje representado, que interpreta como un sello oficial, vinculado al rol de Baria como puerto y centro administrativo del dominio bárquida en la península (Almagro 2017, 434).

En todos estos casos, de nuevo, queda puesto de manifiesto la importancia de los anillos signatorios en la gestión de documentos de registro, y probablemente en el inventario y control de mercancías/producciones.

Este hábito de registro en cualquier caso no es novedoso: en el mundo de la producción cerámica o anfórica, conocemos la difusión de sellos en escritura ibérica y latina tanto sobre ánforas locales Greco-Itálicas y Dr. 1, dolia (de finales del s. II o ya principios del s. I a.n.e., Olesti 2017; Ferrer 2008), y sobre morteros (Díaz 2009). Incluso en algunos casos conocemos ejemplos de sellos ibéricos sobre producciones anteriores a la conquista romana. No hay duda, sin embargo, que con la presencia romana este hábito se incrementó. La difusión del marcaje de los productos cerámicos, que en su mayor parte parecen hacer referencia al productor de la pieza (y no a su contenido), nos indica que las necesidades de registro e inventario se incrementaron a lo largo de los ss. II-I a.n.e., sin duda vinculadas a la difusión de las formas de gestión 
y producción de este tipo de objetos promovidas por la presencia romana. La difusión de los anillos signatorios, y lo que es más importante, la importancia en mostrar y comunicar la identidad de su poseedor, es un fenómeno que no puede desligarse del surgimiento de nuevas formas sociales, políticas y económics de identidad personal, vinculadas sin duda a las fuertes transformaciones de los ss. II-I a.n.e.

\section{Conclusiones}

El conjunto de instrumentos de escritura y registro de los ss. II-I a.n.e. documentados en el NE peninsular, todavía provisional, muestra una realidad hasta hace poco tiempo poco valorada en los estudios sobre este periodo histórico: la existencia de una alfabetización mayor de la documentada, y que abarca muy diversos tipos de yacimientos, entre los que destaca especialmente los de filiación indígena.

No es fácil pronunciarse sobre unos textos no conservados, cuyo reflejo arqueológico es indirecto. Sin embargo, el número de objetos inventariados, y su diversa localización, permiten observar un fenómeno de integración cultural (y quizás lingüística) más rápido y antiguo de lo habitualmente considerado.

En este proceso, el papel del ejército, bien documentado en los nuevos yacimientos de tipo logístico identificados en los últimos años, parece jugar un papel muy importante. No parece casual la presencia abundante de instrumentos de escritura en este tipo de establecimientos (en algunos casos, verdaderas stationes), donde el componente estrictamente militar o ya adminitrativo-provincial no es fácil de distinguir. Sin embargo, el hábito de escritura -y en especial de registro, documentado también por el sellado de piezas - fue más allá del estricto ámbito militar u oficial. La eclosión de nuevas formas económicas y sociales, donde sin duda la identidad de los propietarios o artesanos jugaba un nuevo papel, favoreció la difusión de estos instrumentos. El marcaje e inventario de producciones fue paralelo a la difusión del hábito de la escritura, en un mundo donde el marco local, e incluso provincial, estaba dejando lugar a un contexto político y económico cada vez más amplio. 


\section{Apéndice. Inventario de los instrumentos de escritura documentados}

\begin{tabular}{|c|c|c|c|c|c|c|}
\hline Yacimiento & Objeto & Tipo & $\begin{array}{l}\text { Material / } \\
\text { Medidas }\end{array}$ & Contexto & Cronología & Bibl. \\
\hline \multirow[t]{5}{*}{$\begin{array}{l}1.1 . \\
\text { Valentia }\end{array}$} & stylus & $1 \mathrm{~A}$ & $\begin{array}{c}\text { hueso. } \\
7 \text { x } 1 \mathrm{~cm} \text { frag. }\end{array}$ & $\begin{array}{c}\text { Foro. Nivel de } \\
\text { destrucción }\end{array}$ & 75 a.n.e. & Olesti e.p. \\
\hline & stylus & $2 \mathrm{~B}$ & $\begin{array}{c}\text { hueso. } \\
12 \times 0,8 \mathrm{~cm} .\end{array}$ & $\begin{array}{c}\text { Foro. Nivel de } \\
\text { destrucción }\end{array}$ & 75 a.n.e. & Olesti e.p. \\
\hline & stylus & $1 \mathrm{~B}$ & $\begin{array}{c}\text { hueso. } \\
6 \times 0,9 \mathrm{~cm} .\end{array}$ & $\begin{array}{c}\text { Foro. Nivel de } \\
\text { destrucción }\end{array}$ & 75 a.n.e. & Olesti e.p. \\
\hline & $\begin{array}{c}\text { tapa, cápsula } \\
\text { de sello }\end{array}$ & $\begin{array}{l}\text { Artefacts } \\
\text { BTS-3006 }\end{array}$ & $\begin{array}{c}\text { hueso. } \\
3 \times 2,4 \mathrm{~cm} .\end{array}$ & $\begin{array}{c}\text { Foro. Nivel de } \\
\text { destrucción }\end{array}$ & 75 a.n.e. & Olesti e.p. \\
\hline & anillo-sello & & Hierro y vidrio & $\begin{array}{l}\text { Foro. Nivel de } \\
\text { destrucción }\end{array}$ & 75 a.n.e. & Olesti e.p. \\
\hline \multirow[t]{4}{*}{$\begin{array}{c}1.2 . \\
\text { Emporion }\end{array}$} & styli & $1 \mathrm{~B}, 2 \mathrm{~B}$ & $\begin{array}{l}\text { hueso. } \\
7 \text { items }\end{array}$ & Ciudad romana & II-I a.n.e. & $\begin{array}{c}\text { Bozic y } \\
\text { Feugère, } \\
2004,30 .\end{array}$ \\
\hline & $\begin{array}{l}\text { cápsula de } \\
\text { sello }\end{array}$ & Furger $1 \mathrm{~A}, 1 \mathrm{~B}$ & $\begin{array}{l}\text { hueso. } \\
9 \text { items }\end{array}$ & Ciudad romana & II-I a.n.e. & $\begin{array}{c}\text { Ble } 2015, \\
493 .\end{array}$ \\
\hline & $\begin{array}{c}\text { tapa, cápsula } \\
\text { de sello }\end{array}$ & $\begin{array}{l}\text { Artefacts } \\
\text { BTS-4116 }\end{array}$ & $\begin{array}{l}\text { bronce. } \\
2 \times 1,8 \mathrm{~cm} \text {. } \\
\text { Sepullius/ } \\
\text { Mercurio }\end{array}$ & Ciudad romana & $\begin{array}{l}44 \text { a.n.e.?- } \\
\text { augústeo }\end{array}$ & IRC V 151. \\
\hline & anillo-sello & Guiraud 1B & hierro & $\begin{array}{c}\text { Necrópolis } \\
\text { urbana }\end{array}$ & augústeo & $\begin{array}{c}\text { Almagro } \\
1955 .\end{array}$ \\
\hline \multirow[t]{2}{*}{$\begin{array}{c}1.3 . \\
\text { Tarraco }\end{array}$} & styli & $\begin{array}{c}1 \mathrm{~A}, 1 \mathrm{C}, 2 \mathrm{~A} \\
2 \mathrm{C}\end{array}$ & $\begin{array}{l}\text { hueso. } \\
4 \text { piezas }\end{array}$ & Foro & II-I a.n.e. & $\begin{array}{l}\text { Ble } 2015, \\
294 \text {, fig. } 58\end{array}$ \\
\hline & $\begin{array}{l}\text { cápsula de } \\
\text { sello }\end{array}$ & Furger 1B & bronce & Foro & II-I a.n.e. & $\begin{array}{l}\text { Ble } 2015, \\
294 .\end{array}$ \\
\hline \multirow[t]{8}{*}{$\begin{array}{c}1.4 . \\
\text { Baetulo }\end{array}$} & stylus & $2 \mathrm{~A}$ & $\begin{array}{c}\text { hueso. } \\
6 \times 0.7 \mathrm{~cm} \text { frag. }\end{array}$ & HF.87.2013 & I a.n.e. & Olesti e.p. \\
\hline & stylus & $2 \mathrm{~B}$ & $\begin{array}{c}\text { hueso. } \\
10 \times 0.6 \mathrm{~cm} .\end{array}$ & HI.85.15.205 & I a.n.e.. & Olesti e.p. \\
\hline & stylus & $2 \mathrm{~A}$ & $\begin{array}{l}\text { hueso. } \\
10 \times 1 \mathrm{~cm} .\end{array}$ & $\begin{array}{c}\text { PVR.06.20419. } \\
\text { R456 }\end{array}$ & $\begin{array}{l}1^{\text {a }} \text { mitad I } \\
\text { a.n.e. }\end{array}$ & Olesti e.p. \\
\hline & stylus & $1 \mathrm{~A}$ & $\begin{array}{c}\text { hueso. } \\
\text { 10,5 x } 1 \mathrm{~cm} .\end{array}$ & $\begin{array}{c}\text { PVR.06.20420. } \\
\text { R.226 }\end{array}$ & med. I a.n.e & Olesti e.p. \\
\hline & styus & $2 \mathrm{~A}$ & $\begin{array}{c}\text { hueso. } \\
11,5 \times 0,9 \mathrm{~cm} .\end{array}$ & $\begin{array}{c}\text { PVR.06.20357. } \\
\text { R.357 }\end{array}$ & inicios I a.n.e. & Olesti e.p. \\
\hline & stylus & $2 \mathrm{C}$ & $\begin{array}{c}\text { hueso. } \\
9,5 \times 1,1 \mathrm{~cm} .\end{array}$ & $\begin{array}{c}\text { PVR.06.20419. } \\
\text { R.455 }\end{array}$ & $\begin{array}{l}1^{\text {a }} \text { mitad I } \\
\text { a.n.e. }\end{array}$ & Olesti e.p. \\
\hline & stylus & $2 \mathrm{~B}$ & $\begin{array}{c}\text { hueso. } \\
9,5 \times 0,8 \mathrm{~cm} .\end{array}$ & $\begin{array}{c}\text { PVR.06.20420. } \\
\text { R. } 225\end{array}$ & med. I a.n.e. & Olesti e.p. \\
\hline & stylus & $1 \mathrm{~A}$ & $\begin{array}{c}\text { hueso. } \\
7 \text { x } 0,9 \mathrm{~cm} \text {. frag. }\end{array}$ & AC.2.11.1583.6 & I a.n.e. & Olesti e.p. \\
\hline
\end{tabular}


Los instrumentos de escritura y registro en el noreste peninsular en época repúblicana (s. II-I a.n.e.) como indicadores de romanización

\begin{tabular}{|c|c|c|c|c|c|c|}
\hline Yacimiento & Objeto & Tipo & $\begin{array}{l}\text { Material / } \\
\text { Medidas }\end{array}$ & Contexto & Cronología & Bibl. \\
\hline & stylus & $2 \mathrm{~A}$ & $\begin{array}{c}\text { hueso. } \\
5,5 \times 0,8 \mathrm{~cm} . \\
\text { frag. }\end{array}$ & AC.2.11.1473. & I a.n.e. & Olesti e.p. \\
\hline & stylus & $1 \mathrm{~A}$ & $\begin{array}{l}\text { hueso. } \\
7 \times 0,7 \mathrm{~cm} .\end{array}$ & AC.2.11.1331. & I a.n.e. & Olesti e.p. \\
\hline & $\begin{array}{l}\text { tapa, cápsula } \\
\text { de sello }\end{array}$ & Furger 1B & $\begin{array}{l}\text { hueso. } \\
3 \times 2 \mathrm{~cm} \text {. }\end{array}$ & & I a.n.e. & Olesti e.p. \\
\hline $\begin{array}{l}1.5 . \\
\text { Iluro }\end{array}$ & $\begin{array}{l}\text { cápsulas de } \\
\text { sello }\end{array}$ & Furger 1B & $\begin{array}{l}\text { bronce. } \\
7 \text { piezas. }\end{array}$ & Domus urbana & med. I a.n.e. & $\begin{array}{c}\text { Garcia } \\
2003,36 .\end{array}$ \\
\hline \multirow[t]{5}{*}{$\begin{array}{l}1.6 . \\
\text { Ilerda }\end{array}$} & stylus & $2 \mathrm{~A}$ & $\begin{array}{c}\text { hueso. } \\
8 \times 0,7 \mathrm{~cm} .\end{array}$ & Oppidum & $\begin{array}{l}1^{\text {a }} \text { mitad I } \\
\text { a.n.e. }\end{array}$ & Olesti e.p. \\
\hline & $\begin{array}{l}\text { cápsula de } \\
\text { sello }\end{array}$ & Furger 1B & $\begin{array}{c}\text { hueso. } \\
3,5 \times 2,5 \mathrm{~cm} .\end{array}$ & Oppidum & $\begin{array}{l}1^{\text {a }} \text { mitad I } \\
\text { a.n.e. }\end{array}$ & Olesti e.p. \\
\hline & $\begin{array}{l}\text { tapa, capsula } \\
\text { de sello }\end{array}$ & Furger 1B & $\begin{array}{l}\text { hueso. } \\
2 \times 1,7 \mathrm{~cm} .\end{array}$ & Oppidum & $\begin{array}{l}1^{\text {a }} \text { mitad I } \\
\text { a.n.e. }\end{array}$ & Olesti e.p. \\
\hline & $\begin{array}{l}\text { entalle, anillo- } \\
\text { sello. }\end{array}$ & forma oval & $\begin{array}{c}\text { cornalina. } \\
0,9 \times 1 \times 0,2 \mathrm{~cm} .\end{array}$ & $\begin{array}{c}\text { Ciudad romana. } \\
\text { La Paeria }\end{array}$ & $\begin{array}{l}\text { I a.n.e.- } \\
\text { augústeo }\end{array}$ & $\begin{array}{c}\text { Pérez 1998, } \\
190 .\end{array}$ \\
\hline & sylus & $2 \mathrm{~A}$ & $\begin{array}{l}\text { hueso. } \\
6 \times 0,8 \mathrm{~cm} .\end{array}$ & $\begin{array}{c}\text { Ciudad romana. } \\
\text { La Paeria }\end{array}$ & $\begin{array}{l}\text { I a.n.e.- } \\
\text { augústeo }\end{array}$ & Sabaté e.p. \\
\hline \multirow[t]{2}{*}{$\begin{array}{c}1.7 . \\
\text { Ruscino }\end{array}$} & stylus & $2 \mathrm{~A}$ & $\begin{array}{c}\text { hueso. } \\
9 \times 0,7 \mathrm{~cm} .\end{array}$ & $\begin{array}{l}\text { Silo. Oppidum. } \\
\text { RUS } 1968 \text { S8 }\end{array}$ & 175-125 a.n.e. & $\begin{array}{c}\text { Rebé 2016, } \\
260 .\end{array}$ \\
\hline & styli & $2 \mathrm{~A}, 1 \mathrm{~B}$ & $\begin{array}{c}\text { hueso. } \\
6 \times 0,7 \mathrm{~cm} . \\
7 \times 0,7 \mathrm{~cm} .\end{array}$ & $\begin{array}{l}\text { Silos. Oppidum } \\
\text { RUS } 1991004\end{array}$ & $125-75$ a.n.e. & $\begin{array}{c}\text { Rebé } 2016 \\
\text { fig. } 7,28- \\
29 .\end{array}$ \\
\hline \multirow[t]{2}{*}{$\begin{array}{c}2.1 . \\
\text { Cabrera de } \\
\text { Mar }\end{array}$} & stylus & $1 \mathrm{C}$ & $\begin{array}{l}\text { hueso. } \\
6 \times 0,8 \mathrm{~cm} \text {. }\end{array}$ & $\begin{array}{l}\text { Logístico } \\
\text { romano. } \\
\text { UE } 1042\end{array}$ & 80 a.n.e. & Olesti e.p. \\
\hline & stylus & $1 \mathrm{~A}$ & $\begin{array}{c}\text { hueso. } \\
10 \times 0,8 \mathrm{~cm} .\end{array}$ & $\begin{array}{l}\text { Logístico } \\
\text { romano. } \\
\text { UE } 1042\end{array}$ & 80 a.n.e. & Olesti e.p. \\
\hline \multirow[t]{5}{*}{$\begin{array}{l}2.2 . \\
\text { Camp de les } \\
\text { Lloses }\end{array}$} & stylus & $2 \mathrm{~A}$ & $\begin{array}{l}\text { hueso. } \\
12 \times 1 \mathrm{~cm} \text {. }\end{array}$ & $\begin{array}{l}\text { Logístico } \\
\text { romano. } \\
\text { M.T. } 776\end{array}$ & $120-80$ a.n.e. & $\begin{array}{l}\text { Duran et } \\
\text { al. } 2008, \\
124 .\end{array}$ \\
\hline & caja de sello & $1 \mathrm{~A}$ & $\begin{array}{c}\text { hueso. } \\
2,5 \times 2 \mathrm{~cm} .\end{array}$ & $\begin{array}{l}\text { Logístico } \\
\text { romano. } \\
\text { M.T. } 777\end{array}$ & $120-80$ a.n.e. & $\begin{array}{c}\text { Duran et } \\
\text { al. } 2008, \\
124 .\end{array}$ \\
\hline & $\begin{array}{l}\text { bisagras de } \\
\text { tabula }\end{array}$ & $\begin{array}{c}\text { no } \\
\text { identificable }\end{array}$ & $\begin{array}{c}\text { hierro. } \\
1,5 \times 0.9 \mathrm{~cm} .\end{array}$ & $\begin{array}{c}\text { Logístico } \\
\text { romano. } \\
\text { M.T. 778-779 }\end{array}$ & $120-80$ a.n.e. & $\begin{array}{l}\text { Duran et } \\
\text { al. } 2008, \\
124 .\end{array}$ \\
\hline & spatula & Feugère A1 & hierro & $\begin{array}{l}\text { Logístico } \\
\text { romano. }\end{array}$ & $120-80$ a.n.e. & $\begin{array}{l}\text { Ble } 2015, \\
299 .\end{array}$ \\
\hline & anillo-sello & $\begin{array}{l}\text { Guiraud } \\
\text { 2.G. Figura } \\
\text { humana }\end{array}$ & $\begin{array}{l}\text { hierro y oro. } \\
2,3 \times 2 \mathrm{~cm} .\end{array}$ & & & $\begin{array}{c}\text { Duran et } \\
\text { al. } 2008, \\
118 .\end{array}$ \\
\hline
\end{tabular}




\begin{tabular}{|c|c|c|c|c|c|c|}
\hline Yacimiento & Objeto & Tipo & $\begin{array}{l}\text { Material / } \\
\text { Medidas }\end{array}$ & Contexto & Cronología & Bibl. \\
\hline & anillo-sello & $\begin{array}{l}\text { Guiraud } \\
\text { 2. Figura } \\
\text { humana y } \\
\text { falo. }\end{array}$ & $\begin{array}{c}\text { hierro. } \\
2,5 \times 2,3 \mathrm{~cm} .\end{array}$ & & & $\begin{array}{c}\text { Duran et } \\
\text { al. } 2008, \\
119 .\end{array}$ \\
\hline $\begin{array}{c}2.3 . \\
\text { Monteró }\end{array}$ & styli & desconocidos & varias piezas & $\begin{array}{l}\text { Logístico } \\
\text { romano }\end{array}$ & $120-80$ a.n.e. & $\begin{array}{c}\text { Naco y } \\
\text { Principal } \\
2012,165 .\end{array}$ \\
\hline \multirow[t]{5}{*}{$\begin{array}{c}2.4 . \\
\text { Cardona }\end{array}$} & stylus & $2 \mathrm{~B}$ & $\begin{array}{c}\text { hueso. } \\
8,5 \times 0,7 \mathrm{~cm} .\end{array}$ & $\begin{array}{l}\text { Logístico } \\
\text { romano }\end{array}$ & 120-70 a.n.e. & $\begin{array}{l}\text { Pancorbo } \\
\text { et al. e.p. }\end{array}$ \\
\hline & stylus & $1 \mathrm{~B}$ & $\begin{array}{c}\text { hueso. } \\
6 \times 0,4 \mathrm{~cm} .\end{array}$ & $\begin{array}{c}\text { Logístico } \\
\text { romano }\end{array}$ & $120-70$ a.n.e. & $\begin{array}{l}\text { Pancorbo } \\
\text { et al. e.p. }\end{array}$ \\
\hline & stylus & $2 \mathrm{~A}$ & $\begin{array}{c}\text { hueso. } \\
7 \times 0,4 \mathrm{~cm} .\end{array}$ & $\begin{array}{l}\text { Logístico } \\
\text { romano }\end{array}$ & $120-70$ a.n.e. & $\begin{array}{l}\text { Pancorbo } \\
\text { et al. e.p. }\end{array}$ \\
\hline & $\begin{array}{l}\text { tapa, cápsula } \\
\text { de sello }\end{array}$ & Furger 1A & $\begin{array}{l}\text { hueso. } \\
3 \times 2,5 \mathrm{~cm} .\end{array}$ & $\begin{array}{c}\text { Logístico } \\
\text { romano }\end{array}$ & 120-70 a.n.e. & $\begin{array}{l}\text { Pancorbo } \\
\text { et al. e.p. }\end{array}$ \\
\hline & entalle & forma oval & $\begin{array}{c}\text { vidrio. } \\
2 \times 2 \mathrm{~cm} . \\
\text { ¿figura divina? }\end{array}$ & $\begin{array}{l}\text { Logístico } \\
\text { romano }\end{array}$ & 120-70 a.n.e. & $\begin{array}{l}\text { Pancorbo } \\
\text { et al. e.p. }\end{array}$ \\
\hline \multirow[t]{4}{*}{$\begin{array}{c}2.5 . \\
\text { Tossal de } \\
\text { Baltarga }\end{array}$} & $\begin{array}{c}\text { anillo-sello y } \\
\text { entalle }\end{array}$ & Guiraud 1B & \begin{tabular}{|c|} 
hierro. \\
$2,1 \times 2,1 \times 16,5 \mathrm{~cm}$. \\
Gema: \\
$1,7 \times 1,5 \mathrm{~cm}$. \\
Aquiles y \\
Pentesilea
\end{tabular} & $\begin{array}{l}\text { Logístico } \\
\text { romano }\end{array}$ & 150-40 a.n.e. & $\begin{array}{l}\text { Oller et al. } \\
\text { e.p. }\end{array}$ \\
\hline & anillo-sello & Guiraud 1B & $\begin{array}{l}\text { hierro y oro. } \\
1,8 \times 1,2 \times 0,9 \mathrm{~cm}\end{array}$ & $\begin{array}{c}\text { Logístico } \\
\text { romano }\end{array}$ & 150-40 a.n.e. & $\begin{array}{l}\text { Oller et al. } \\
\text { e.p. }\end{array}$ \\
\hline & $\begin{array}{c}\text { anillo-sello } \\
\text { con entalle de } \\
\text { pasta vítrea }\end{array}$ & Guiraud 1C & $\begin{array}{c}\text { bronce. } \\
1,6 \times 1,7 \times 0,8 \mathrm{~cm} . \\
\text { Pasta vítrea. } \\
0,8 \times 0,7 \mathrm{~cm}\end{array}$ & $\begin{array}{l}\text { Logístico } \\
\text { romano }\end{array}$ & $150-40$ a.n.e. & $\begin{array}{l}\text { Oller et al. } \\
\text { e.p. }\end{array}$ \\
\hline & anillo-sello & Guiraud 2G & $\begin{array}{c}\text { plata. } \\
3 \times 2 \mathrm{~cm} .\end{array}$ & $\begin{array}{l}\text { Alrededores } \\
\text { Logístico } \\
\text { romano }\end{array}$ & & $\begin{array}{l}\text { Oller et al. } \\
\text { e.p. }\end{array}$ \\
\hline $\begin{array}{l}3.1 . \\
\text { St. Julià de } \\
\text { Ramis }\end{array}$ & stylus & $1 \mathrm{~A}$ & $\begin{array}{c}\text { hueso. } \\
6 \times 0,9 \mathrm{~cm}\end{array}$ & $\begin{array}{l}\text { Oppidum. } \\
\text { Área de la } \\
\text { puerta. } \\
\text { UE 3394-3423, } \\
3429 \\
\end{array}$ & 120 -100 a.n.e. & $\begin{array}{l}\text { Burch et al. } \\
2011,135 .\end{array}$ \\
\hline \multirow[t]{3}{*}{$\begin{array}{c}3.2 . \\
\text { Burriac }\end{array}$} & stylus & $\begin{array}{l}\text { Cabeza en } \\
\text { forma de } \\
\text { delfín }\end{array}$ & $\begin{array}{c}\text { plata. } \\
11 \times 0,9 \mathrm{~cm} .\end{array}$ & Oppidum & II a.n.e. & $\begin{array}{c}\text { Barberà } \\
\text { y Pascual } \\
1979,229 .\end{array}$ \\
\hline & tábula & & madera de tilo & Oppidum & II a.n.e. & $\begin{array}{c}\text { Barberà } \\
\text { y Pascual } \\
1979,229 .\end{array}$ \\
\hline & anillo-sello & Furger 1B & $\begin{array}{c}\text { bronce. } \\
2,5 \times 2,3 \mathrm{~cm} .\end{array}$ & Oppidum & $\begin{array}{l}1^{\circ} \text { cuarto I } \\
\text { a.n.e. }\end{array}$ & $\begin{array}{c}\text { Ribas y } \\
\text { Lladó 1977, } \\
161 .\end{array}$ \\
\hline
\end{tabular}


Los instrumentos de escritura y registro en el noreste peninsular en época repúblicana (s. II-I a.n.e.) como indicadores de romanización

\begin{tabular}{|c|c|c|c|c|c|c|}
\hline Yacimiento & Objeto & Tipo & $\begin{array}{l}\text { Material / } \\
\text { Medidas }\end{array}$ & Contexto & Cronología & Bibl. \\
\hline & stylus & & hueso & Oppidum. Puerta & $\begin{array}{l}1^{\mathrm{a}} \text { mitad I } \\
\text { a.n.e. }\end{array}$ & Olesti e.p. \\
\hline & stylus & & hueso & Oppidum. Puerta & $\begin{array}{l}1^{\text {a }} \text { mitad I } \\
\text { a.n.e. }\end{array}$ & Olesti e.p. \\
\hline \multirow[t]{4}{*}{$\begin{array}{c}\text { 3.3. } \\
\text { Torre dels } \\
\text { Encantats }\end{array}$} & stylus & $2 \mathrm{~A}$ & $\begin{array}{c}\text { hueso. } \\
\text { 12,5 x } 1 \mathrm{~cm} \text {. }\end{array}$ & Oppidum & $\begin{array}{c}\text { s. II- } \\
\text { mediados s. I } \\
\text { a.n.e. }\end{array}$ & $\begin{array}{c}\text { Garcés } \\
2013,269 .\end{array}$ \\
\hline & stylus & $1 \mathrm{~A}$ & $\begin{array}{l}\text { hueso. } \\
10 \times 1 \mathrm{~cm} .\end{array}$ & Oppidum & $\begin{array}{l}\text { II-med. I } \\
\text { a.n.e }\end{array}$ & $\begin{array}{c}\text { Garcés } \\
2013,269 .\end{array}$ \\
\hline & ¿calamus? & & $\begin{array}{c}\text { bronce. } \\
4 \times 0,9 \mathrm{~cm} .\end{array}$ & Oppidum & $\begin{array}{l}\text { II-med. I } \\
\text { a.n.e. }\end{array}$ & $\begin{array}{c}\text { Garcés } \\
2013,252 .\end{array}$ \\
\hline & $\begin{array}{l}\text { pondera } \\
\text { sellados }\end{array}$ & & $\begin{array}{c}\text { cerámica. } \\
5,8 \times 4,2 \times 2,5 \mathrm{~cm} \text {. } \\
\text { gema: } 1,5 \times 1 \mathrm{~cm} .\end{array}$ & Oppidum & $\begin{array}{l}\text { II-med. I } \\
\text { a.n.e. }\end{array}$ & $\begin{array}{c}\text { Garcés } \\
2013,234 .\end{array}$ \\
\hline $\begin{array}{c}3.4 . \\
\text { Turó del } \\
\text { Vent }\end{array}$ & stylus & $\begin{array}{c}\text { Schaltebrand } \\
\text { A6-B2-C1 }\end{array}$ & $\begin{array}{c}\text { bronce. } \\
8 \times 0,7 \mathrm{~cm} .\end{array}$ & Oppidum & $\begin{array}{c}\text { Inicios II } \\
\text { a.n.e. }\end{array}$ & $\begin{array}{l}\text { López y } \\
\text { Sanmartí } \\
\text { 1986, } 95 .\end{array}$ \\
\hline $\begin{array}{c}3.5 . \\
\text { Torre Roja }\end{array}$ & stylus & $2 \mathrm{~A}$ & $\begin{array}{c}\text { hueso. } \\
5,5 \times 1 \mathrm{~cm} .\end{array}$ & Oppidum & $\begin{array}{l}1^{\text {a }} \text { mitad I } \\
\text { a.n.e. }\end{array}$ & Inédito. \\
\hline \multirow[t]{3}{*}{ 3.6. Olèrdola } & stylus & $2 \mathrm{~B}$ & $\begin{array}{l}\text { hueso. } \\
9 \times 1 \mathrm{~cm} .\end{array}$ & Oppidum & $\begin{array}{l}1^{\text {a }} \text { mitad I } \\
\text { a.n.e. }\end{array}$ & $\begin{array}{c}\text { Molist } \\
2016,242 .\end{array}$ \\
\hline & stylus & $1 \mathrm{~B}$ & $\begin{array}{c}\text { hueso. } \\
9 \times 0,7 \mathrm{~cm} .\end{array}$ & & $\begin{array}{l}1^{\text {a }} \text { mitad I } \\
\text { a.n.e. }\end{array}$ & $\begin{array}{c}\text { Molist } \\
2016,242 .\end{array}$ \\
\hline & anillo-sello & Guiraud 2G & $\begin{array}{c}\text { plata. } \\
\text { diám. } 4,5 \mathrm{~cm} .\end{array}$ & Oppidum & $\begin{array}{l}1^{\text {a }} \text { mitad I } \\
\text { a.n.e. }\end{array}$ & $\begin{array}{c}\text { Molist } \\
2016,242 .\end{array}$ \\
\hline $\begin{array}{c}3.7 . \\
\text { L'Esquerda }\end{array}$ & $\begin{array}{c}\text { Tapa, cápsula } \\
\text { de sello }\end{array}$ & Furger 1B & $\begin{array}{l}\text { hueso. } \\
3 \times 2 \mathrm{~cm}\end{array}$ & Oppidum & $\begin{array}{l}\text { s. II-med. s. I } \\
\text { a.n.e. }\end{array}$ & Olesti e.p. \\
\hline \multirow[t]{2}{*}{$\begin{array}{c}3.8 . \\
\text { Sigarra }\end{array}$} & caja de sello & Furger $1 \mathrm{~A}-1 \mathrm{~B}$ & hueso & Oppidum & $\begin{array}{l}\text { s. II-med. s. I } \\
\text { a.n.e. }\end{array}$ & $\begin{array}{c}\text { Salazar } \\
2018,38 .\end{array}$ \\
\hline & stylus & $1 \mathrm{~A}$ & hueso & Oppidum & $\begin{array}{l}\text { s. II-med. s. I } \\
\text { a.n.e. }\end{array}$ & $\begin{array}{c}\text { Salazar } \\
2018,38 .\end{array}$ \\
\hline \multirow[t]{5}{*}{$\begin{array}{c}\text { 3.9. } \\
\text { St. Miquel } \\
\text { de Sorba }\end{array}$} & styli & $\begin{array}{c}1 \mathrm{~A}, 1 \mathrm{C}, 2 \mathrm{~A} \\
2 \mathrm{~B}\end{array}$ & hueso, 5 piezas & $\begin{array}{l}\text { Oppidum. } \\
\text { Ex. } 1930 .\end{array}$ & & $\begin{array}{c}\text { Ble } 2015, \\
293 .\end{array}$ \\
\hline & stylus & $1 \mathrm{~A}$ & $\begin{array}{c}\text { hueso. } \\
4 \times 1 \mathrm{~cm} \text {. frag. }\end{array}$ & Oppidum & $\begin{array}{l}\text { s. II-med. s. I } \\
\text { a.n.e. }\end{array}$ & $\begin{array}{l}\text { Ble } 2015 \text {, } \\
\text { lám. } 59 .\end{array}$ \\
\hline & stylus & $\begin{array}{c}\text { Schaltebrand } \\
\text { A4-B1-C2 }\end{array}$ & $\begin{array}{c}\text { bronce. } \\
10 \mathrm{x}, 1,2 \mathrm{~cm}\end{array}$ & Oppidum & $\begin{array}{l}\text { s. II- med. s. I } \\
\text { a.n.e. }\end{array}$ & $\begin{array}{l}\text { Ble } 2015 \text {, } \\
\text { lám. } 59 .\end{array}$ \\
\hline & $\begin{array}{c}\text { tapa, cápsula } \\
\text { de sello }\end{array}$ & Furger 1A & hueso & $\begin{array}{l}\text { Oppidum. } \\
\text { Ex. } 1930 .\end{array}$ & & $\begin{array}{c}\text { Ble } 2015, \\
296 .\end{array}$ \\
\hline & doble spatula & Feugère B1 & $\begin{array}{c}\text { hierro. } \\
13 \times 2,5 \mathrm{~cm} .\end{array}$ & $\begin{array}{l}\text { Oppidum. } \\
\text { Ex. } 1930 .\end{array}$ & & $\begin{array}{l}\text { Ble } 2015, \\
299 .\end{array}$ \\
\hline \multirow[t]{2}{*}{$\begin{array}{c}3.10 . \\
\text { Castellot }\end{array}$} & doble spatula & Feugere B1 & $\begin{array}{c}\text { hierro. } \\
13,5 \text { x } 2,5 \mathrm{~cm} .\end{array}$ & Oppidum & $\begin{array}{l}\text { med. II-med. } \\
\text { I a.n.e. }\end{array}$ & $\begin{array}{c}\text { Morera et } \\
\text { al. } 2019 .\end{array}$ \\
\hline & anillo-sello & Guiraud 1B & $\begin{array}{c}\text { hierro. } \\
1,5 \times 0,8 \text { (roto) }\end{array}$ & Oppidum & $\begin{array}{l}\text { med. II-med. } \\
\text { I a.n.e. }\end{array}$ & $\begin{array}{l}\text { Morera et } \\
\text { al. } 2019 .\end{array}$ \\
\hline
\end{tabular}




\begin{tabular}{|c|c|c|c|c|c|c|}
\hline Yacimiento & Objeto & Tipo & $\begin{array}{l}\text { Material / } \\
\text { Medidas }\end{array}$ & Contexto & Cronología & Bibl. \\
\hline $\begin{array}{c}3.11 . \\
\text { Gebut, Soses }\end{array}$ & anillo-sello & Guiraud 2G & $\begin{array}{c}\text { Plata. Ónice con } \\
\text { cabeza barbada. } \\
\text { Inscripción } \\
\text { ibérica }\end{array}$ & Necrópolis & II-I a.n.e. & $\begin{array}{c}\text { Pujol 1890; } \\
M L H \\
\text { D.11.1. }\end{array}$ \\
\hline $\begin{array}{c}3.12 . \\
\text { P. Castellar de } \\
\text { Sta. Coloma }\end{array}$ & $\begin{array}{l}\text { pondera } \\
\text { sellados }\end{array}$ & & $\begin{array}{c}\text { cerámica. } \\
10 \times 15 \times 5 \mathrm{~cm} \\
\text { gema: } 1 \times 1 \mathrm{~cm}\end{array}$ & $\begin{array}{c}\text { Silos ubicados } \\
\text { bajo el oppidum }\end{array}$ & 100-50 a.n.e. & $\begin{array}{c}\text { De la Pinta } \\
1993,146 .\end{array}$ \\
\hline $\begin{array}{c}3.13 . \\
\text { Torre } \\
\text { de la Sal } \\
\text { (Castellón) }\end{array}$ & caja de sello & Furger 1B & bronce & Oppidum & II-I a.n.e. & Flors 2009. \\
\hline \multirow[t]{2}{*}{$\begin{array}{c}3.14 . \\
\text { Son Espases } \\
\text { (Mallorca) }\end{array}$} & styli & $2 \mathrm{~A}$ & $\begin{array}{l}\text { hueso. } \\
10 \times 1 \mathrm{~cm} \text {. }\end{array}$ & $\begin{array}{l}\text { Logístico } \\
\text { romano }\end{array}$ & 125-50 a.n.e. & $\begin{array}{l}\text { Estarellas et } \\
\text { al. 2014, } 8 .\end{array}$ \\
\hline & spatula & Feugère B1 & bronce & $\begin{array}{l}\text { Logístico } \\
\text { romano }\end{array}$ & 125-50 a.n.e. & Olesti e.p. \\
\hline \multirow[t]{2}{*}{$\begin{array}{c}3.15 . \\
\text { Marinesque } \\
\text { (Francia). }\end{array}$} & stylus & $2 \mathrm{~A}$ & $\begin{array}{l}\text { hueso. } \\
8 \times 1 \mathrm{~cm} \text {. }\end{array}$ & Statio & 100-50 a.n.e. & $\begin{array}{c}\text { Bermond et } \\
\text { al. } 2016 .\end{array}$ \\
\hline & $\begin{array}{c}\text { tapa, cápsula } \\
\text { de sello }\end{array}$ & Furger 1A & $\begin{array}{l}\text { hueso. } \\
3 \times 2 \mathrm{~cm} \text {. }\end{array}$ & Statio & 100-50 a.n.e. & Olesti e.p. \\
\hline
\end{tabular}

\section{Referencias de las tipologías:}

Cajas de sellos: Furger et al 2009; Artefacts.mom.fr.

Spatulae: Feugère 1995.

Anillos-sello: Guiraud 1989.

Styli de metal: Schaltenbrand 2012.

Styli de hueso: Elaboración propia.

Grupo 1. Stylus cónico simple.
1A. Mango homogéneo.
1B. Con apéndice final.
1C. Con mango engrosado.
1D. Con apéndice final y mango engrosado (no documentado).

Grupo 2. Stylus cónico complejo. Con inflexión (o muesca) entre la cabeza y el mango.
2A. Mango homogéneo.
2B. Con apéndice final.
2C. Con mango engrosado.
2D. Con apéndice final y mango engrosado (no documentado). 


\section{INSTRUMENTOS DE ESCRITURA. TIPOLOGÍA}

GRUPO 1. Stylus cónico simple

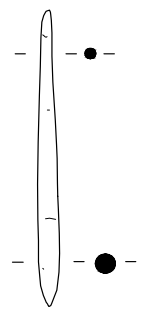

Tipo 1 A. Mango homogéneo Estilete de Torre dels Encantats

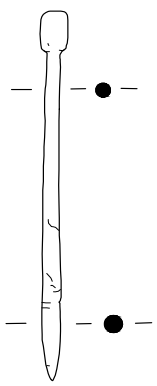

Tipo 1B. Con apéndice final Estilete de Cardona

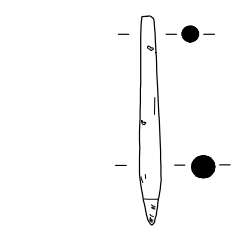

Tipo 1C. Cabrera. Mango engrosado Estilete de Cabrera de Mar

GRUPO 2. Stylus cónico complejo. Con inflexión (o muesca) entre la cabeza y el mango.

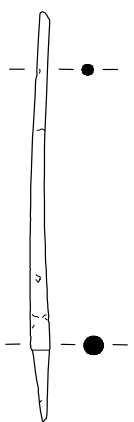

Tipo 2A. . Mango homogéneo. Estilete de Cardona.

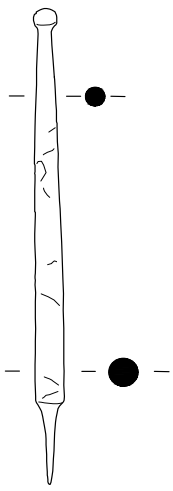

Tipo 2B. Con apéndice final. Estilete de Cardona

\section{ANILLO SIGNATORIO}

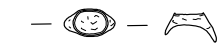

Anillo de hierro. Superfície dorada (Ag-Au). Tossal de Baltarga.

Caja de sello de hueso, tipo Furger 1a. Cardona.

Fig. 2. Instrumentos

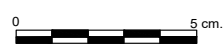

de escritura, tipología (elaboración propia).

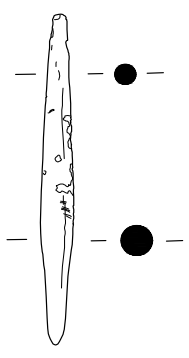

Tipo 2C. Con mango engrosado. Estilete de Baetulo

\section{ESPÁTULA}

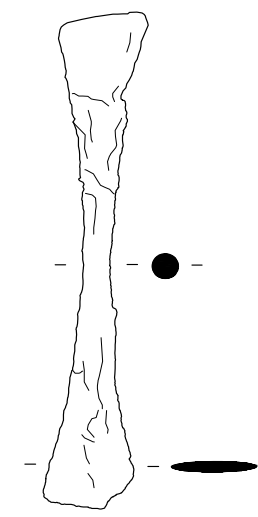

Doble espátula de hierro El Castellot de Bolvir. 
Agradecimientos: Este trabajo no hubiera sido posible sin la ayuda de un gran número de arqueólogos e investigadores que nos han ofrecido desinteresadamente su colaboración y nos han abierto sus almacenes y registros. Desde aquí, les agradecemos a todos ellos su ayuda e interés y en especial a J. Ferrer, M. Estarellas, J. Merino, F. Torres, I. Simón y A. Mayayo así como a los revisores anónimos de este artículo sus indicaciones, que en la medida de lo posible hemos intentado incorporar al texto.

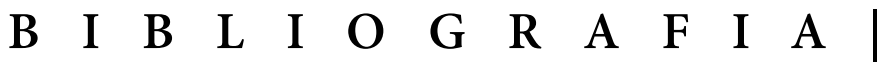

Adams 2003: J. N. Adams, Bilingualism and the Latin language, Cambridge 2003.

Almagro 2017: M. Almagro, "Una crétula con 'Jinete con lanza' en el Museo de Jaén”, en: J. de Santiago y J. M. de Francisco (eds.), Homenaje a María Ruiz Trapero, Madrid 2017, 405-435.

Andrews, C. 2013: C. Andrews, “Are Roman seal-boxes evidence for literacy?”, JRA 26, 2013, 423-438.

Aquilué y Carreras 2000: X Aquilué y T. Carreras (eds.), "La formació d’una societat provincial. La component iberica a les fundacions rornanes del nord-est de la Hispania citerior”, Empúries 52, 2000, 9-185.

Barberà y Pascual 1979-80: J. Barberá y R. Pascual, "Burriac, un yacimiento protohistórico de la costa catalana (Cabrera de Mar, Barcelona)”, Ampúrias 41-42, 1979-80, 203-242.

Barrandon 2013: N. Barrandon, "Approche technique des pratiques épigraphiques dans la péninsule Ibérique au Ier millénaire av. J.-C., MCV 43.1, 2013, 173-197.

Beltrán 2005: F. Beltrán, "Cultura escrita, epigrafía y ciudad en el ámbito paleohispánico", PalHisp 5, 2005, 21-56.

Bermond et al. 2016: I. Bermond, M. Christol, M. Feugère, Ch. Pellecuer y Ch. Sanchez, "Marinesque (Loupian, Hérault) : un relais routier sur la voie Domitienne", Gallia 73.1, 41-70.

Ble 2015: E. Ble, Guerra y conflicto en el nordeste de Hispania durante el periodo romanorepublicano (218-45 a.C.). La presencia del ejército romano a partir de sus evidencias arqueológicas metálicas, Tesis doctoral, Universidad de Barcelona 2015.

Bozic y Feugère 2004: D. Bozic y M. Feugère, "Les instruments de l'écriture", Gallia 61, 2004, 21-41.

Burch, Nolla y Sagrera 2011: J. Burch, J. M. Nolla y J. Sagrera, Excavacions arqueològiques a la muntanya de St. Julià de Ramis. 4. Les defenses de l’oppidum de Kerunta, Girona 2011.

Castanyer, Santos y Tremoleda, 2015: P. Castanyer, M. Santos y J. Tremoleda, "Una nueva fortificación de época republicana en Empúries. Una base militar para la conquista de Hispania", en: M. Bendala (ed.), Los Escipiones. Roma conquista Hispania, Madrid 2015, 107-127.

Cela, Garcia y Pera 2003: X. Cela, J. Garcia y J. Pera, Iluro, una Ciutat per descubrir, Mataró 2003.

Cura 1971: M. Cura, "Acerca de unas cerámicas grises con decoración estampillada en la Catalunya prerromana", Pyrenae 7, 1971, 47-60. 
De Hoz, Díaz y Ribera 2013: M. P. de Hoz, B. Díaz y A. Ribera, "Grafitos sobre cerámica procedentes de los niveles romanorrepublicanos de Valentia (Valencia, España)", PalHisp 13, 2013, 407-429.

De la Pinta 1993: J. de la Pinta, "Estampillas sobre producciones cerámicas ibéricas. Una aportación a su catálogo", Gala 2, 1993, 143-156.

Demierre 2015: M. Demierre, "Le petit mobilier des fouilles récentes de la ZAC Niel à Toulouse (Haute-Garonne). Chronologie, caractérisation des assemblages et contacts avec le monde méditerranéen" en: S. Raux (ed.) Actualité de la recherche sur les mobiliers non céramiques de l'Antiquité et du haut Moyen Âge, Chauvigny 2015, 157-180.

Derks y Roymans 2002: T. Derks y N. Roymans, "Seal-boxes and the spread of Latin literacy in the Rhine delta", en: A. Cooley (ed.), Becoming Roman, writing latin? Literacy and epigraphy in the Roman West, Portsmouth 2002, 87-134.

Díaz 2009: B. Díaz "La Hispania Citerior, desarrollo económico e integración en época republicana: una aproximación epigráfica”, DHA 35.1, 2009, 115-152.

Duran, Mestres y Principal 2008: M. Duran, I. Mestres y J. Principal, Les col-leccions de l'exposició permanent del Camp de les Lloses (Tona), Tona 2008.

Eckhardt, 2017: H. Eckhardt, Writing and Power in the Roman World: Literacies and Material Culture, Cambridge 2017.

Estarellas, Merino y Torres 2014: M. Estarellas, J. Merino y F. Torres, Roma conquesta Mallorca. Les excavacions a Son Espases, Palma 2014.

Ferrer 2008: J. Ferrer, "Ibèric tagiar. Terrissaires que signen les seves produccions: biurko, ibeitiger, biur bedi i companyia", Sylloge Epigraphica Barcinonensis 6, 2008, 81-93.

Feugère 1995: M. Feugère,"Les spatules à cire à manche figuré", en: W. Czysz et al. (eds.), Provincial Römische Forschungen: Festschrift für Günther Ulbert, Múnich 1995, 321-338.

Flors 2009: E. Flors (ed.), Torre La Sal (Ribera de Cabanes, Castellón). Evolución del paisaje antrópico desde la prehistoria hasta el medioevo, Castellón 2009.

Fortó y Maese 2011: A. Fortó y X. Maese, "La Torre Roja: un jaciment ibèric i medieval (Caldes de Montbui, Vallès Oriental)”, Tribuna d'Arqueologia 2009-2010, 2011, 113-152.

Furger, Wartmann y Riha 2009: A. Furger, F. Wartmann y E. Riha, Die römischen Siegelkapseln aus Augusta Raurica, Augst 2009.

Garcés 2013: I. Garcés, Catàleg dels materials arqueològics de la Torre dels Encantats. Col-lecció del Museu d'Arenys de Mar, Arenys de Mar 2013.

Guiraud 1989: H. Guiraud, "Bagues et anneaux à l'époque romaine en Gaule”, Gallia 46, 1989, 173-211

Hanson y Conolly 2002: W. S. Hanson y H. C. Conolly, "Language and literacy in Roman Britain: some archaeological considerations", en: A. Cooley (ed.), Becoming Roman, writing latin? Literacy and epigraphy in the Roman West, Portsmouth 2002, 151-164.

López, Rovira y Sanmartí 1986: A. López, J. Rovira y J., Sanmartí, Excavaciones en el poblado layetano del Turó del Vent. Llinars del Vallés. Campañas 1980 y 1981, Barcelona 1986.

López, Alonso y Bernal 2018: J. López, N. Alonso y J. Bernal, "Loppidum ibèric de Gebut (Soses): avanç dels resultats de la campanya del 2017", RAP 28, 2018, 247-282.

Marshman 2015: I. J. Marshman, Making Your Mark in Britannia. An investigation into the use of signet rings and intaglios in Roman Britain. Tesis Doctoral, University of Leicester, 2015.

Mayayo e.p.: A. Mayayo"Instrumentos de escritura en hueso procedentes de la Cabañeta (Burgo de Ebro, Zaragoza)", en: H. Uroz (ed.), Cultura material romana en la Hispania republicana, Lezuza, en prensa. 
Mayer 2014: M. Mayer, "Signata nomina; sobre el concepto y valor del término signaculum con algunas consideraciones sobre el uso de los instrumentos que designa”, en: A. Buonopane y S. Braito (ed.), Instrumenta Inscripta V. Signacula ex aere, Roma 2014, 11-34.

MLH III: J. Untermann, Monumenta Linguarum Hispanicarum. Die iberischen Inschriften aus Spanien, Wiesbaden 1990.

Minguez y Díaz 2011: J. A. Mínguez y B. Díaz, "Grafitos sobre cerámica -ibéricos, latinos, griegos y signos- procedentes del yacimiento romanorrepublicano de La Cabañeta (El Burgo de Ebro, Zaragoza)", AEspA 84, 2011, 51-86.

Molist 2014: N. Molist, "La fortificación tardorepublicana de Olèrdola y el control del acceso norte a Tarraco", en: F. Sala (ed.), Las huellas de las guerras civiles romanas en el sureste de Hispania, Alicante 2014, 227-245.

Morera, Olesti y Oller 2016: J. Morera, O. Olesti y J. Oller, "El control del Pirineo en época ibérica y romana republicana", en: J. Pera (ed.), Fortificaciones y control del territorio en la Hispania Republicana, Zaragoza 2016, 137-166.

Noguera, Principal y Ñaco, 2014: J. Noguera, J. Principal y T. Naco, "La actividad militar y la problemática de su reflejo arqueológico en el caso del Nordeste de la Citerior (218-45 a.C.), en: F. Cadiou y M. Navarro (eds.) La guerre et ses traces. Conflites et sociétés en Hispanie à lépoque de la conquête romaine (s. III-I a.C.), Bordeaux 2014, 31-56.

Nolla y Castanyer 2010: J. M. Nolla y P. Castanyer (eds.), Time of changes. In the beginning of the Romanization. Studies on the rural world in the Roman Period, 5. Girona-Banyoles 2010.

Naco 2010: T. Naco, "Garrisons, military logistics and civil population in the Late Republic: Africa and Hispania”, en: C. Carreras y R. Morais (eds.), The Western Roman Atlantic Façade: A Study of the Economy and Trade in the Mar Exterior from the Republic to the Principate, Oxford 2010, 145-150.

Ñaco 2017: T. Naco, “Conectividad, integración military y 'estrés bélico’ en el N.E. de Hispania Citerior (125-100 a.C.)”, en: J. Principal, T. Naco, M. Durán, I. Mestres (ed.), Roma en la Península ibérica presertoriana. Escenarios de implantación militar y provincial, Barcelona 2017, 17-38.

Olesti 2000: O. Olesti, "Integració i transformació de les comunitats ibèriques del Maresme durant els s. II-I a.C.: un model de romanització per a la Catalunya litoral i prelitoral", Empúries 52, 2000, 55-86.

Olesti 2010: O. Olesti, “Urbanització, integració i gestió del territori al nord-est de la península ibèrica en època republicana (s. II-I a.C.)", en: Time of changes. In the beginning of the Romanization. Studies on the rural world in the Roman Period 5, Girona 2010, 11-60.

Olesti 2017: O. Olesti, "La génesis de la sociedad provincial y el proceso de urbanización en el Noreste de la Península Ibérica (siglos II-I a.C.)”, Gerión 35-2, 2017, 69-102.

Olesti e.p.: O. Olesti, “'Next please!': Writing, using seals and the making of registries during the Roman Conquest in N.E. Hispania., JRA en prensa.

Ollich, Rocafiguera y Amblàs 2014: I. Ollich, M. Rocafiguera y O. Amblàs, "Loppidum ibèric de l'Esquerda: darreres aportacions i noves línies de recerca", en: II Jornades d'Arqueologia de la Catalunya Central, Vic 2014, 118-124.

Padrós y Ruiz 2015: C. Padrós y J. Ruiz de Arbulo, "Castella i praesidia a la façana Mediterrània de la Hispania Republicana”, RAP 25, 2015, 229-325.

Pancorbo, Martín y Olesti e.p: A. Pancorbo, A. Martín y O. Olesti, "La explotación y el control de la sal en época romana en Cardona (II-I a.n.e.): el yacimiento del Campet de la Sal", en: III International Congress on the Anthropology of Salt. Añana, $12^{\text {th }}-15^{\text {th }}$ September 2018, en prensa. 
Pera y Vidal 2016: J. Pera y J. Vidal (eds.) Fortificaciones y control del territorio en la Hispania Republicana, Zaragoza 2016.

Pombo 2014: G. M. Pombo Cravinho, Glíptica romana en Portugal, Tesis Doctoral, Universidad de Santiago de Compostela, 2014.

Principal et al. 2017: J. Principal, T. Naco, M. Durán e. I. Mestres, Roma en la Península ibérica presertoriana. Escenarios de implantación militar y provincial, Barcelona 2017

Pujol 1890: C. Pujol, “Un anillo ibérico”, Boletín de la Real Academia de la Historia 16, 1890, 163-169

Purcell 2001: N. Purcell, “The ordo scribarum: a study in the loss of memory”, MEFRA 113.2, 2001, 633-674.

Rebé 2016: I. Rebé, “Les Stylets de Ruscino”, en: G. Baratta (ed.), Studi su Ruscino, Barcelona 2016, 253-262.

Ribas y Lladó 1977: M. Ribas y J. Lladó, “Excavació d’unes habitacions pre-romanes a Burriac (Cabrera de Mataró)", Pyrenae 13-14, 1977, 153-180.

Ribera 2014: A. Ribera, "La destrucción de Valentia (75 a.C.) y la cultura material de la época de Sertorio (82-75 a.C.)", en: F. Sala (ed.), Las huellas de las guerras civiles romanas en el sureste de Hispania, Alicante 2014, 63-75.

Ribera 2017: A. Ribera, "Contextos cerámicos de Valentia (Hispania) entre su fundación (138 a.C.) y su destrucción (75 a.C.)”, en: SFECAG, Actes du Congrés de Narbonne, Narbona 2017, 517-542.

Salazar 2018: N. Salazar, Segarra-Sikarra, Cruïlla entre Ibèria I Hispania, Prats de Rei 2018.

Sarri 2018: A. Sarri, Material Aspects of Letter Writing in the Graeco-Roman World, Berlín 2018.

Schaltenbrand 2012: V. Schaltenbrand, Stilus: Kulturhistorische, typologisch-chronologische und technologische Untersuchungen an römischen Schreibgriffeln von Augusta Raurica und weiteren Fundorten, Augst 2012.

Schenk 2008: A. Schenk, Regard sur la tabletterie antique. Les objets en os, bois de cerf et ivoire du Musée Romain d'Avenches, Lausana 2008.

Simón 2012: I. Simón, "La primera inscripción ibérica sobre una gema (La Guardia de Alcorisa, Teruel)", ZPE 181, 2012, 303-309.

Simón 2016: I. Simón, "El esclavo refugiado en el altar: una escena de la comedia griega en un entalle del Palomar de Oliete (Teruel), en: $I^{\text {er }}$ Congreso de Arqueologia y Patromonio Aragonés, Zaragoza 2016, 383-38.

Simón 2018: I. Simón, "La epigrafía de El Palomar de Oliete: cultura escrita en un poblado ibérico", RAP 28, 2018 11-30.

Simón e.p.: I. Simón, "Los estilos de hueso en los yacimientos del Valle medio del Ebro", en H. Uroz (ed.), Cultura material romana en la Hispania Republicana, Lezuza, en prensa.

Sinner y Ferrer 2016: A. G. Sinner y J. Ferrer i Janè, "Del oppidum de Burriac a las termas de Ca l'Arnau. Una aproximación a la lengua y la identidad de los habitants de Ilduro (Cabrera de Mar)", AEspA 89, 2016, 193-223.

Sinner y Velaza 2019: A. G. Sinner y J. Velaza (eds.), Paleohispanic Languages and Epigraphies, Oxford 2019.

Vaquerizo, Quesada y Murillo 2011: B. Vaquerizo, F. Quesada y J. F. Murillo, Protohistoria y romanización en la Sudbética Cordobesa, Córdoba 2011.

Woolf 1994: G. Woolf, "Power and the spread of writing in the west", en: A. K. Bowman y G. Woolf (eds.), Literacy and Power in the Ancient World, Cambridge 1994, 84-98. 